\title{
FRAY TORIBIO MOTOLINÍA: LA VISIÓN URBANA DE UN CRONISTA NOVOHISPANO. BREVE SEMBLANZA SOBRE EL DISEÑO DE LOS ESPACIOS URBANOS Y RELIGIOSOS EN TLAXCALA DURANTE EL SIGLO XVI
}

\author{
Óscar Armando GARCÍA GUTIÉRREZ \\ Universidad Nacional Autónoma de México
}

Pocos años después de la caída de Tenochtitlan en 1521 (y de esta manera consumada la Conquista), fray Toribio de Benavente o Motolinía iniciaba la redacción de una de las crónicas más reveladoras sobre el primer proceso de evangelización durante el siglo XVI: su Historia de los indios de la Nueva España (obra que en adelante será citada como HINA, y siguiendo la ed. de O'Gorman 1990). La importancia de estos textos' reside en su calidad como valiosa fuente de información, tanto para los cronistas seráficos de fines del XVI, como, por supuesto, para la historiografía contemporánea dedicada la estudio de este período ${ }^{2}$.

En este artículo pretendemos identificar aquellas menciones específicas sobre el diseño y manejo de los diferentes espacios urbanísticos y arquitectónicos relativos primordialmente a la celebración religiosa, basándonos en los tres Tratados en los que está compuesta esta crónica. También tomaremos en cuenta aque-

1 Nos referimos en plural por la problemática de edición crítica que tiene la obra. Recordemos que podemos localizar tres referencias del mismo material: la Historia..., los Memoriales y el «Libro perdido». Sobre este asunto, ver el Estudio crítico de Edmundo O'Gorman en la edición citada.

2 Por ejemplo, la historiografía dedicada a estudiar en particular el fenómeno del teatro de evangelización en la Nueva España ha tenido la referencia obligada del célebre capítulo 15 del Tratado I de la HINA, donde el cronista hace una descripción privilegiada sobre las fiestas de Corpus Christi, efectuadas en Tlaxcala en 1538. 
llos espacios relacionados con otros fenómenos de representación religiosa ${ }^{3}$, descritos en la misma crónica. Proponemos este procedimiento para poder reconstruir, hipotéticamente, los pasos que se dieron dentro del primer proceso constructivo de la urbanización y la arquitectura de Tlaxcala, durante las primeras décadas de la colonización hispana.

Cualquier fenómeno arquitectónico puede revisarse históricamente, tomando en consideración los elementos descritos en una fuente histórica, como lo es la crónica elegida. Dentro de este artículo, trataremos de configurar un modesto catálogo de formas arquitectónicas y urbanas que nos permitan replantear una reconstrucción del fenómeno constructivo en su forma y en su etapa de elaboración. De esta manera, podremos apreciar de mejor manera el funcionamiento que pudieron haber tenido los diferentes espacios y edificios constitutivos de conjuntos conventuales, dilucidando, en el sentido estricto, la relación que estos espacios y edificaciones tuvieron con la construcción y planeación de una de las primeras ciudades hispanas en territorio americano. Por lo tanto, trataremos de alejarnos del fácil camino de la generalización y procuraremos distinguir, de manera crítica, el fenómeno del uso y diseño de estos espacios urbanísticos dentro del contexto mismo de estos primeros procesos de occidentalización en América ${ }^{4}$.

Los criterios para utilizar solamente la crónica de Motolinía se deben, primero, a las dimensiones del artículo y, segundo, porque las otras fuentes importantes (Muñoz Camargo, Bartolomé de las Casas, Mendieta) de alguna u otra manera vuelven a utilizar el material de Motolinía ${ }^{5}$.

Nuestro trabajo tratará de responder los siguientes cuestionamientos: ¿De qué manera los procesos de evangelización en Tlaxcala tuvieron en consideración el espacio como elemento de conversión religiosa? ¿En qué nivel del proceso

Con el término representación nos referiremos constantemente a aquellos fenómenos que no necesariamente tienen una implicación teatral, sino más bien tienen un implicación de tipo ritual, donde conviven una serie de individuos en una misma celebración, sin la dicotomía actor-espectador, sino más bien la de participantes.

4 Es hasta hace muy poco tiempo que los estudiosos comienzan a hacer una relación entre arquitectura y los procedimientos y metodologías de evangelización. La tendencia, incluso, había sido la del olvido con respecto al arte colonial, pues se le había dado preponderancia al arte prehispánico y al barroco.

No utilizaremos tampoco los Memoriales porque, justamente el capítulo 15, Tratado I de la HINE no se encuentra en esta obra. Al respecto, O'Gorman nos aclara que: «En los Memoriales no aparecen los capítulos correspondientes a Historia, Trat. I, cap. 15;》 (O'Gorman 1990, nota 16, p. XIV). Y puntualiza: «los capítulos 13,14 y 15 de la Historia deberían estar, de acuerdo con la secuencia en Memoriales, en el Tratado II con los números 3, 4, y 5 , porque ya no se refieren al culto idolátrico que es la materia del Tratado Y.». (ibid, nota 1, Cap. 13, p. 54). No podemos olvidar los valiosos testimonios de Antonio de Ciudad Real, Tratado curioso y docto de las grandezas de la Nueva España, sin embargo tampoco será utilizado en este estudio por no corresponder a la etapa de evangelización analizada. 
constructivo se encontraban las edificaciones religiosas tlaxcaltecas para el 1538 ? ¿Fueron utilizadas las capillas abiertas como escenarios para la representación teatral? ¿Qué espacios fueron diseñados para otros tipos de representación religiosa? Pretendemos que en este ejercicio historiográfico el material de la crónica de fray Toribio vaya respondiendo paulatinamente a todos estos cuestionamientos, sin marginar algunos testimonios de otros cronistas contemporáneos a Motolinía, valiosos para la reconstrucción que nos proponemos hacer en este trabajo, lo que nos permitirá ver con detenimiento cómo se fueron diseñando los espacios urbanísticos en Tlaxcala.

\section{II}

La conversión religiosa en la Nueva España tuvo diferentes etapas. La primera la podemos localizar desde la llegada del clero regular desde 1523 en sus distintas misiones (franciscanos, dominicos y agustinos) hasta la realización de la Segunda Audiencia. La segunda etapa reconocible podemos ubicarla entre 1531 hasta 1550 aproximadamente. Esta etapa, donde podemos localizar gran parte de los acontecimientos narrados en la crónica por Motolinía, estará marcada justamente por el apogeo de la labor evangelizadora (con el apoyo decisivo del Virrey Antonio de Mendoza), la demarcación de las principales rutas misioneras, la organización del Colegio de Tlatelolco y la construcción de los grandes conjuntos conventuales.

Fray Toribio de Benavente (o Motolinía, su nombre de adopción indígena) arribó a las costas mexicanas junto con el primer grupo de franciscanos españoles $^{6}$, también conocida como el grupo de «los Doce» en 1524; este grupo estuvo comandado por el célebre Fray Martín de Valencia. El tránsito inicial y estadía en tierras mexicanas de Fray Toribio, después de su llegada a las costas del Golfo, será Texcoco, México, Huejotzingo, Puebla y Tehuantepec, antes de su trabajo como guardián del convento de Tlaxcala, en 1536.

Como él, varios de sus compañeros llegaron a México haciendo una riesgosa travesía por barco de varios meses. ¿Qué pudo haber sucedido en la mente de todos ellos durante la travesía? ¿Cómo se imaginarían al Nuevo Mundo, a sus habitantes? Pocos, desafortunadamente, son los registros de estas reflexiones que nos han quedado hasta nuestros días, pero lo que podemos suponer es que el

6 No olvidemos que un año antes ya habían llegado tres misioneros franciscanos flamencos (Pedro de Gante, Juan de Tecto y Juan de Aora), pero que, sin embargo, no habían podido organizar cabalmente un programa concreto de evangelización. De todas maneras, para el grupo de los Doce será de gran valía la experiencia de Gante durante ese año, convirtiéndose en uno de los más importantes estrategas de esta primera etapa misionera. 
pensamiento de cada uno de ellos, como individuos, estaba fincado en proyectos o en ideales que se ya se habían experimentado en evangelizaciones en Europa.

Varios de estos hermanos de la pobreza pudieron pensar, sin problema, en la llegada a una especie de paraíso prometido, donde sus habitantes vivían en armónica relación con la naturaleza; estos pensamientos pudieron haber estado precedidos por la imaginería mitológica de las nuevas tierras, difundida años antes por los navegantes descubridores y por los primeros conquistadores ${ }^{7}$. La literatura apologética franciscana de fines del siglo será la encargada de revalorizar este pensamiento dentro de una especie de Edad Dorada ${ }^{8}$.

Es muy probable que en la mente de algunos de estos frailes ultramarinos pudiera haber existido el ideal de encontrarse con una especie de «jardín» habitado por gentiles, el cual debería transformarse en la ideal Civitas Dei agustiniana. Transformar este «jardín» en un lugar de culto: este fue uno de los primeros objetivos que el programa evangelizador tenía que incorporar en los primeros pasos de la acción franciscana al llegar a los dominios recientemente conquistados. Aquellos frailes que tuvieran una incipiente formación de los oficios constructivos, tenían la misión de comenzar este diseño 9 .

\section{III}

Los procesos constructivos de conjuntos conventuales, durante este primer proceso de evangelización, tuvieron características generales que podemos identificar de la siguiente manera (presentados sin un orden estricto): localización del asentamiento principal, desde donde se iniciaría la búsqueda de otros sitios; construcción del incipiente convento (generalmente hecho de paja y madera); construcción de capillas-visitas como puntos de referencia del área a evangelizar; edificación de la capilla abierta; delimitación del patio atrial; si el sitio del convento era el indicado, entonces se continuaba con el diseño y construcción definitivas; traza de la ciudad, tomando como punto axial la plaza civil, o bien el mismo conjunto conventual.

7 Sobre el imaginario mitológico de los conquistadores, recomendamos la lectura de la primera parte de la obra de Weckmann 1984.

8 Un ejemplo característico de narración histórica de esta «Edad Dorada» de la evangelización es la obra Historia Eclesiástica Indiana de Fray Jerónimo de Mendieta.

9 Para una información más completa sobre los primeros procesos constructivos de edificaciones religiosas, sigue siendo de gran utilidad la consulta de los capítulos II, III y IV de la obra de Kubler 1992; sin embargo falta aún profundizar en la filiación real de los verdaderos constructores y arquitectos de los conjuntos conventuales y tomar el texto de Kubler como una referencia interesante. Por ejemplo, este autor llega a aseverar que la crónica de Motolinía apenas tuvo referencias hacia los procesos constructivos de Tlaxcala. 
Tlaxcala fue construida bajo este patrón aproximado, en constantes ensayos de localización de los sitios adecuados, como podremos observarlo a través del artículo.

De inicio, Motolinía nos brinda dos pasajes donde se plantea, por un lado, la forma en que los propios indígenas colaboraron en la localización de la construcción del templo cristiano:

Y los indios señores y principales delante de los frailes destruían sus ídolos, y levantaban cruces y señalaban sitios para hacer sus iglesias (Trat. II, Cap. 1, p. 79).

y por el otro, la manera como se iban asentando las bases de los primeros procesos constructivos y las primeras fuentes de material utilizados en los templos:

$Y$ al principio [los indígenas] por cumplir con los frailes comenzaron a demandar que les diesen las imágenes, y a hacer algunas ermitas y adoratorios, y después iglesias, y ponían en ellas imágenes y con todo esto siempre procuraron de guardar sus templos sanos y enteros; aunque después, yendo las cosas adelante, para hacer las iglesias comenzaron a echar mano de sus teocallis para sacar de ellos piedra y madera, y de esta manera quedaron desollados y derribados; y los ídolos de piedra, de los cuales había infinitos, no sólo escaparon quebrados y hechos pedazos, pero vinieron a servir de cimientos para las iglesias (Trat. I, Cap. 3, p. 22).

Para los frailes era importante la búsqueda de un sitio que tuviera acceso inmediato a materiales para la construcción del templo cristiano y la cercanía a alguna fuente de agua (río, arroyo, manantial, etcétera) para el mantenimiento vital del futuro convento. Haciendo un balance general de observación sobre los asentamientos de los diferentes lugares religiosos (conventos o parroquias), los sitios no eran construidos, como se ha pretendido manejar, obligatoriamente encima de los antiguos centros o adoratorios indígenas, sino más bien buscaban lugares alejados a éstos para no promover la idolatría. Los centros ceremoniales indígenas, en general, se encontraban en la punta de peñascos y cerros que no ofrecían ninguna solución práctica desde el punto de vista urbano ${ }^{10}$. En realidad, los ejemplos de construcción de templos cristianos sobre los templos indígenas resultan excepcionales.

En el caso de la ciudad de Tlaxcala, como en varias regiones de la Nueva España, el primer convento (hoy desaparecido y de materiales perecederos) fue ubicado en las inmediaciones del pueblo de Maxixcatzin; posteriormente fue edificado en Cuitlixco (ca. 1526) y finalmente se comenzó con el diseño y construcción del aposento que actualmente conocemos, dedicado a la Asunción

10 En general estos peñascos o puntas de cerros van a ser aprovechados por los frailes para establecer ermitas o grandes cruces. 
de Nuestra Señora (o también conocido como convento de San Francisco Tlaxcala), hacia el 1540 (Cf. Gibson 1991, pp. 52-54). La fenomenología anteriormente descrita nos aclarará que los frailes necesitaban estudiar muy bien la ubicación de sus conventos, tomando en consideración diversos factores, como la aceptación de la población indígena, problemas topográficos, ubicación con respecto a poblados indígenas, emplazamiento estratégico de la evangelización en la zona, etcétera. En el caso de Tlaxcala es clara la intención de los frailes de aprovechar el valle y las inmediaciones del río para tener un amplio control de los antiguos asentamientos indígenas de los cuatro reinos tlaxcaltecas: Tepetipac, OcoteculcoMaxixcatzin, Tizatlán y Quiahuiztlan (Cf. HINE, Trat. III, Cap. 16, pp. 185-186).

La disposición del conjunto conventual con respecto a la plaza de los poderes civiles en Tlaxcala es un interesante testimonio de los diferentes criterios que estaban en juego mientras se consolidaba la ciudad durante este primer período de evangelización.

\section{IV}

Los primeros conventos franciscanos tlaxcaltecas tuvieron una fisonomía particular. Las necesidades de espacios dentro del edificio no tenían mucha diferencia de sus modelos europeos, tomando en consideración que se requerían básicamente los mismos elementos (capilla, claustro, dormitorios, refractario, cocina, huerto, sala de lectura), sin embargo comenzaron a añadirse algunos elementos que tuvieron que adecuarse a las circunstancias mismas de la evangelización. Estos elementos, fundamentalmente, serían la capilla abierta y el patio atrial.

Los patios (hoy conocidos como atrios) fueron necesarios para albergar a una gran cantidad de fieles conversos mientras eran concluidas las obras de la capilla principal. En este caso, el punto de culto era la capilla abierta, que ofrecía la posibilidad de agrupar a los fieles durante las misas al aire libre y también utilizada como centro de formación catequística. Un antecedente (o probable inspiración funcional) del patio la expone Motolinía al describir los patios de los templos indígenas o teocalis de la siguiente manera:

Llámanse estos templos teucallis, y hallamos en toda esta tierra, que en lo mejor del pueblo hacían un gran patio cuadrado; (...) Este patio cercábanle de pared, y muchos de ellos eran almenados; guardaban sus puertas a las calles y caminos principales, que todos los hacían que fuesen a dar al patio, y por honrar más sus templos sacaban los caminos muy derechos por cordel... (Trat. I, Cap. 12, p. 50).

La cita marca, de manera curiosa, ciertas analogías con patios atriales de conventos tlaxcaltecas construidos posteriormente, en donde aún podemos adver- 
tir esta tendencia de incorporar las calles que comunican al convento con los diferentes barrios del poblado. Bartolomé de las Casas hace una referencia a estos patios. Observemos la semejanza de la siguiente descripción con la anterior:

El patio que dice aquí [Motolinía] es una plaza grande cerrada de almenas, obra de un estado del suelo, poco más o menos, blanqueados de cal, muy lindas, que hacen los indios delante de la puerta de cada iglesia, donde caben treinta y cuarenta y cincuenta mil personas, cosa mucho de ver (Las Casas 1967. Tomo I, Capítulo LXIV, p. 333).

Cuando Motolinía narra en su crónica las primeras actividades de conversión religiosa, aprovecha la ocasión para situarlas en el espacio correspondiente:

En este tiempo se comenzó a encender otro fuego de devación en los corazones de los indios que se bautizaban, cuando deprendían el Ave María, y el Pater Noster, y la doctrina cristiana; (...) Fue tanta la prisa que se dieron a deprenderla [el canto llano], y como la gente era mucha, estábanse a montoncillos así en los patios de las iglesias y ermitas como por (sus) barrios. (Trat. I, Cap. 4, p. 25)

El dato relevante de este pasaje es la distribución que comenzaba a dársele a los principales puntos de devoción: los patios de iglesias y los barrios. El patio, sin embargo, se convirtió en el espacio de encuentro más importante en este activo proceso de evangelización, sobre todo para el bautismo:

A un fraile aconteció que (...) bautizando en un gran patio a muchos indios, que aún entonces no había iglesias... (Trat. III, Cap. 3, p. 130)

Siguiendo de manera muy aproximada el proceso constructivo de los primeros conjuntos conventuales, el patio tuvo un estrecho nexo con la presencia de la capilla abierta, como lo mencionamos anteriormente. Motolinía hace su primera referencia a esta construcción cuando describe las fiestas y pascuas del Señor y de Nuestra Señora:

...y estos bailes y cantos comienzan a medianoche en muchas partes, y tienen muchas lumbres en sus patios, que en esta tierra los patios son muy grandes y muy gentiles, porque la gente es mucha, y no caben en las iglesias, y por esto tienen su capilla fuera de los patios, porque todos oyen misa todos los domingos y fiestas, y las iglesias sirven para entre semana (Trat. I, Cap. 13, p. 54).

La cita anterior pone en entredicho la hipótesis generalizada de que las capillas abiertas habían sido diseñadas debido al pánico que los indígenas tenían de los recintos internos. Motolinía justamente nos ofrece una explicación muy lógica de adecuación del espacio por la gran cantidad de individuos que participaban en una festividad, efectuada en el patio. Y continúa:

La noche de Navidad ponen mucha lumbres en los patios de las iglesias y en los terrados de sus casas, y como son muchas las casas de azotea, y van las casas una legua, y dos, y más, parecen de noche un cielo estrellado; y generalmente cantan y tañen atabales y campanas, que ya en esta tierra han hecho 
muchas. (..) Los indios en esta noche vienen a los oficios divinos y oyen sus tres misas, y los que no caben en la iglesia por eso no se van, sino delante de la puerta y en el patio rezan y haciendo mismo que si estuviesen dentro (Ibid, pp. 54-55).

Dos son los elementos a destacar de este interesante párrafo: el primero de ellos la sensibilidad de Motolinía para apreciar cómo las festividades cristianas iban siendo adoptadas por los indígenas, transformando al pueblo en un luminoso espacio de representación religiosa. Por otra parte, se insiste en el uso del patio por el sobrecupo que existía en la capilla principal, así como la forma en que este espacio interno es sustituido por el patio.

La capilla abierta estará presente en la crónica de Motolinía en varios pasajes. Una de las más completas es la descripción de la capilla abierta del convento de San Francisco o de la Asunción, hoy desaparecida (ubicada en el patio del convento), que aún podemos ver en la ilustración del códice de Muñoz Camargo (Cf. Muñoz Camargo 1981). Esta capilla tiene, por sus características, una enorme semejanza con la capilla abierta de Tizatlán ${ }^{11}$, hoy en pie, la cual aún conserva sus pinturas murales, pero con una construcción adosada del siglo XVIII que tapa actualmente su fisonomía original. Al observar la ilustración de Muñoz Camargo, al leer la descripción de Fray Toribio y al admirar la capilla abierta de Tizatlán, podemos aventurar la hipótesis de que en ambos ejemplos se trató de un mismo programa constructivo que realizó sendas capillas. Motolinía, nos indica que:

Para la Pascua tenían acabada la capilla del patio, la cual salió una solemnísima pieza; llámanla Belén. Por parte de fuera la pintaron luego a el fresco en cuatro días, porque así las aguas nunca la despintaran; en un ochavo de ella pintaron las obras de la creación del mundo de los primeros tres días, y en otro ochavo las obras de los otros tres días; en otros dos ochavos, en el uno la verga de Jesé, con la generación de la madre de Dios, la cual está en lo alto puesta muy hermosa; en otro está nuestro padre San Francisco; en otra parte está la Iglesia; santo papa, cardenales, obispos, etc.; y a la otra banda el emperador, reyes y caballeros. Los españoles que han visto la capilla, dicen que es de las graciosas piezas que de su manera hay en España. Llevan sus arcos bien labrados; dos coros: uno para los cantores, otro para los ministriles; hízose todo esto en seis meses (Trat. I, Cap. 15, pp. 64-65).

Contamos también con un testimonio de Bartolomé de las Casas. Este pasaje narra una celebración en otro espacio. Es, probablemente, la descripción de lo que Artigas denomina como «humilladero» (Artigas 1992, p. 123) ${ }^{12}$ o también cono-

"La capilla de Tizatlán ha sido analizada recientemente por Juan B Artigas (veáse Artigas 1992, pp. 131-143). También recomendable la consulta del artículo de Toussaint que inició la investigación sobre esta construcción (cf. Toussaint 1927, pp. 173-180).

12 Haciendo una lectura más cuidadosa del edificio, nos aventuraríamos a pensar que más que un humilladero, la edificación era una capilla abierta en prueba de localización, es decir, aún no se definía si se construía la capilla en lo alto de un montículo (a la manera de los teocallis) o integrado a un patio atrial. 
cida como Capilla Abierta de la escalinata, que aún podemos apreciar junto a la actual plaza de toros de Tlaxcala. La importancia de este pasaje es la evidente teatralización de la festividad observada por de Las Casas, quien menciona:

Otra fiesta representaron los mismos indios vecinos de la ciudad de Tlascala el día de Nuestra Señora de la Asumpción, año de mil quinientos y treinta y ocho, en mi presencia, y yo canté la misa mayor porque me lo rogaron los padres de Sant Francisco, y me la oficiaron tres capillas de indios cantores, por canto de órgano, y doce tañedores de flautas con harta melodía y solenidad, y por cierto dijo allí persona harto prudente y discreta que en la capilla del rey no se pudiera mejor oficiar. Fueron los apóstoles, a los que los representaban, indios, como en todos los actos que arriba se han recitado (y esto se ha siempre de suponer que ningún español entiende ni se mezcla en los actos que hacen con ellos), y el que representaba a Nuestra Señora, indio, y todos los que en ello entendían, indios. Decían en su lengua lo que hablaban, y todos los actos y movimientos que hacían con harta cordura y devoción, y de manera que la causaban a los oyentes y que vían lo que se representaba con su canto de órgano de muchos cantores y la música de las flautas cuando convenía, hasta subir a la que representaba a Nuestra Señora en una nube desde un tablado hasta otra altura que tenían hecha por cielo, lo cual todo estaban mirando en un patio grande, a nuestro parecer más de ochenta mill personas (Las Casas 1967, pp. 333-334).

Otro testimonio importante de los patios/capillas de Tlaxcala lo tenemos en la narración de Fray Jerónimo de Mendieta. Sin duda, nos encontramos ante el mismo espacio descrito por de Las Casas:

Yo puedo decir con verdad que la cosa más agradable a la vista que en mi vida he visto, fue ver en Tlascala en tiempos pasados dos patios que tiene la iglesia, uno alto y otro bajo, a do bajan por una real escalera de dos andenes, como la de Arcadi de Roma, patios y escalera llenos de gente apeñuscada con sus ramos en las manos, en tal día como el Domingo de Ramos... (Mendieta en Sempat 1991, p. 196).

El conjunto de estos pasajes denotan la importancia que en su momento tuvo la capilla abierta en Tlaxcala. La función litúrgica que muchas veces se le quiere imponer es desbordada al analizar cada uno de estos eventos descritos por Motolinía y por sus contemporáneos. A las capillas abiertas existentes en la ciudad de Tlaxcala, habríamos que agregar las de Atlihuetzia ${ }^{13}$, Ixtacuixtla, Huejotzingo ${ }^{14}$ y Tepeyanco. Todas ellas son testimonio de la importancia que para la época y la región tuvieron dentro de los procesos de evangelización. Como menciona Gibson:

13 Donde encontramos elementos decorativos de la bóveda de la capilla hechos muy probablemente por el mismo maestro cantero que elaboro la bóveda de la capilla del convento de Tlaxcala.

14 Hasta hace pocos años no se consideraba al convento de Huejotzingo como un ejemplo con capilla abierta, sin embargo, recientes trabajos de arqueología han permitido descubrir el primer proceso constructivo del convento en donde estaba integrado dentro del diseño la capilla abierta. $\mathbf{C f}$. Córdova Tello 1992. 
Es probable que desde el punto de vista de la participación en masa de los indios, la capilla abierta, en vez de la iglesia cerrada o del monasterio, representara el período de máxima energía y celo religioso (Gibson 1991, p. 62).

Sin embargo, los diversos testimonios antes observados también nos permiten aseverar que la importancia de estos espacios no se limitó en sus funciones catequistas y litúrgicas, sino que fueron evidentes escenarios para la ejecución de representaciones teatrales religiosas, con complejos aparatos escénicos a la manera de los deux ex machina griegos, que servian para subir, bajar o hacer aparecer a la Virgen; o bien la marcada intención de decorar estas capillas con un programa iconográfico que, temáticamente, es paralelo a las primeras representaciones de teatro de evangelización. Sin embargo, el panorama de espacios urbanos de representación religiosa en Tlaxcala tiene otros formatos que observaremos a continuación.

\section{V}

Otros artefactos y construcciones provisionales fueron elaborados para las famosas representaciones teatrales de Corpus Christi de 1538. La celebración de estas festividades se llevó a cabo en un complejo diseño de características escénicourbanísticas, el cual comprendía plazas, calles, patios conventuales, capillas abiertas y capillas procesionales de la ciudad de Tlaxcala.

Revisemos brevemente algunos ejemplos contenidos en la crónica. Motolinía hace un catálogo de aquellos elementos utilizados para las diversas representaciones, como por ejemplo los peñones de la procesión de Corpus Christi:

tenían en cuatro esquinas o vueltas que se hacían en el camino, en cada una su montaña, y de cada una salía su peñón bien alto; y desde abajo estaba hecho como prado, con mata de yerba y flores, y todo lo demás que hay en un campo fresco, y la montaña y el peñón tan al natural como si allí hubiese nacido (Trat. I, Cap 15, p. 62).

Prosigue Motolinía con una impresionante descripción de todo lo que contenían estos peñones: aves, liebres, venados, culebras y cazadores con arcos y flechas. Los autos referidos por el autor, se infiere, fueron representados en tablados:

Y luego en adelante en otro tablado representaron la Anunciación de Nuestra Señora... (Idem)

en cadalsos puestos en el patio:

Después en el patio de la iglesia de San Juan a do fue la procesión, luego en allegando antes de misa, en otro cadalso, que no eran poco de ver los cadalsos cuán graciosamente estaban ataviados y enrosados, representaron la Visitación de Nuestra Señora a Santa Elisabet...(Idem); 
y en aparejados ${ }^{15}$, junto a la puerta del Hospital ${ }^{16}$,

Tenían cerca de la puerta del hospital aparejado para representar un auto, que fue la caída de nuestros primeros padres...(Idem).

Todo ello dispuesto en la plaza de Tlaxcala, para la representación de la Conquista de Jerusalén en junio de 1539:

En Tlaxcala, en la ciudad que de nuevo han comenzado a edificar ${ }^{17}$, abajo en lo llano, dejaron en el medio una grande y muy gentil plaza, en la cual tenían hecha a Jerusalén encima de unas casas que hacen para el Cabildo, sobre el sitio que ya los edificios iban en altura de un estado. (Ibid, p. 67)

En este caso, el incipiente conjunto urbanístico de Tlaxcala fue utilizado como una gran escenografía de representación teatral religiosa. Diseño urbanístico y celebración se conjuntaron para organizar los espacios civiles y religiosos, de tal manera que fueran funcionales para sus actividades de devoción colectiva.

\section{VI}

Una última manifestación que queremos abordar es, tal vez, la más significativa, compleja y, a la vez, perdurable, en la memoria urbanística religiosa de Tlaxcala: las procesiones; Motolinía dedica varios pasajes de su obra a la descripción de este fenómeno.

La procesión, de honda herencia medieval, es una de las celebraciones más antiguas del cristianismo. Su celebración creó caminos y cruces en el mapa Europeo en su modalidad de peregrinación. Las procesiones tenían como objetivo recuperar, de manera simbólica, algunos pasajes importantes de la Pasión de Cristo o bien efectuar el paseo de una imagen santa por las calles del pueblo, en estrecha relación con la capilla sede, el día del onomástico de la imagen.

El traslado a la Nueva España de esta tradición, como muchas otras, no fue extraño a los naturales, quienes análogamente también tenían entre sus rituales el paseo de una imagen o bien el desfile con el próximo sacrificado por los barrios, previo a su inmolación. Motolinía comienza a anotar la forma en que los indígenas:

15 El término no pudo haber sido el más correcto para describir un escenario con su tinglado, pues aparejo, según el Diccionario Porrúa de la Lengua Española, es, entre sus varias acepciones, un: «sistema de poleas dispuesto para aumentar la potencia de levantamiento» (p. 49).

16 Se trata del Hospital de la Encarnación de Tlaxcala, terminado, según Motolinía, el Domingo de Ramos de 1537, el 25 de marzo. La construcción se encontraba a un costado del actual edificio conventual de Tlaxcala. Cf. HINE, Trat. II, Cap. 8, p. 102.

17 Cabe notar que Tlaxcala y México eran las primeras ciudades que comenzaban a edificarse bajo los criterios teórico-arquitectónicos de Serlio y Vitrubio, los cuales anunciaban ya una traza cuadricular, partiendo de un centro-eje urbanístico: la plaza. 
Adornan sus iglesias muy pulidamente con los paramentos que pueden haber, y lo que les hace falta de tapicería suplen con muchos ramos, flores, espadañas y juncia, que en esta tierra se ha multiplicado cosa increíble y por donde tiene que pasar la procesión hacen muchos arcos triunfales, hechos de rosas... (Trat. I, Cap. 13, p. 54).

El pasaje nos indica la forma en que, de manera organizada, los indígenas comenzaban a establecer sus puntos de referencia entre camino de la procesión e iglesia, sin olvidar el acento sensible de la presencia aromática durante la celebración (juncia, rosas, ramos y flores).

Los caminos procesionales o calles adquieren un sentido inusual durante la celebración. Las calles de tránsito cotidiano se transforman, durante la procesión, en espacios de representación activa para los participantes:

Por el camino tienen puestos árboles grandes, y en algunas partes que ellos mismos están nacidos allí, suben los niños, y unos cortan ramos y los echan por el camino al tiempo que pasan las cruces, otros encima de los árboles cantan, otros muchos van echando sus ropas y mantas en el camino, y éstas son tantas que casi siempre van las cruces y los ministros sobre mantas (Trat. I, Cap. 13 , p. 55 ).

Otro pasaje interesante es el que Motolinía incluye en el mismo capítulo donde se describen las fiestas de Corpus Christi de 1538. Al igual que en la cita anterior, se utilizaron caminos tapizados con juncia y flores, decorados con arcos, andas con aderezos adornados de pluma y oro y

...hubo muchas maneras de danzas que regocijaban la procesión. Había en el camino sus capillas con sus altares y retablos bien aderezados para descansar, a donde salían de nuevo los niños cantores cantando y bailando delante del Santísimo Sacramento (Trat. I, Cap. 15, p. 61).

Añadimos al breve catálogo de construcciones religiosas las capillas procesionales, que podemos encontrar en las calles, en el camino de la procesión, o bien en los patios atriales. De esta tradición se derivan las capillas posas que se localizan en puntos angulares de los patios, o también las capillas procesionales permanentes que se construyeron en algunos otros conventos.

Continuando con las procesiones, basten dos ejemplos más para culminar este amplio panorama de uso espacial en los eventos religiosos. El primero explica la manera en que se iban adecuando las calles para el paso de las procesiones:

Estaban diez arcos triunfales grandes muy gentilmente compuestos; y lo que era más de ver y para notar, era que tenían toda la calle a la larga hecha en tres partes como naves de iglesias; en la parte de enmedio había veinte pies de ancho; por ésta iba el Sacramento y ministros y cruces con todo el aparato de la procesión, y por los otros dos de los lados que eran de cada quince pies, iba toda la gente, que en esta ciudad y provincia no hay poca; y este apartamiento 
era todo hecho de unos arcos medianos que tenían de hueco a nueve pies; y de estos había por cuenta mil y sesenta y ocho arcos... (Trat. I, Cap. 15, pp. 61-62).

El segundo ejemplo nos permite imaginar la articulación que pudo haber existido entre dos o más lugares por donde pasaba la procesión. En este caso específico, se sigue la descripción de la procesión de Corpus de 1538 y se destaca de nuevo el uso de la escalinata del convento de San Francisco de Tlaxcala:

Para la procesión de este día (...) Había seis capillas con sus altares y retablos (...). Había también tres montañas contrahechas muy a el natural con sus peñones, en las cuales se representaron tres autos muy buenos. En la primera, que estaba luego abajo del patio alto, en otro patio bajo a do se hace una gran plaza, aquí se representó la tentación del Señor (...). Pasando la procesión a otra plaza, en otra montaña se representó cómo San Francisco predicaba a las aves (...). Pasando adelante el santísimo Sacramento había otro auto, y era del sacrificio de Abraham, el cual por ser corto y ser ya tarde no se dice más de que fue muy bien representado. Y con esto volvió la procesión a la iglesia (Ibid, pp. 73-74).

Analizando este pasaje, podemos destacar la manera en que esta procesión sirvió, efectivamente, de eje de articulación para la presentación de estos autos (algunos de ellos en tablados) que funcionaban como estaciones, diseminados en diferentes puntos de la ciudad, a la manera de las representaciones medievales. Sería interesante tratar de reconstruir el camino que siguió esta procesión, y las diferentes representaciones teatrales, en un mapa de la ciudad de Tlaxcala.

Para el año de estas celebraciones, los indígenas habían tenido muy poco tiempo para establecer los nuevos códigos religiosos que estaban presentes en las imágenes y estandartes que encabezaban estas procesiones. El indígena participaba en las procesiones por la cercanía que este evento tenía con sus antiguos mitotes y tocotines, pero tal vez se encontraba lejano o ajeno a la imagen a consagrar. Como lo indica Gruzinski:

El contacto [del indígena] con la imagen se desarrolló habitualmente en un marco de liturgia o de catequesis. Se seguía a las imágenes que comentaba el sacerdote, o se rezaba ante ellas ${ }^{18}$.

Pero, así como se estaba dando este contacto con las imágenes, también se estaba realizando una conversión del espacio urbano, donde la imposición y la adopción fueron factores comunes dentro de esta etapa inicial de evangelización. Eran momentos donde no existía, para esta nueva colectividad novohispana, una frontera entre espacios civiles y religiosos, entre espacios cotidianos y rituales. Es apenas el tiempo de definiciones y negociaciones entre aquellos que comienzan a convivir en este peculiar período de transferencia cultural.

18 «Al descubrir la imagen pintada o grabada, los indios no podían dejar de tropezar con un conjunto exótico y hermético de convenciones iconográficas» (Gruzinski 1994, p. 84). 


\section{VII}

La Historia de los indios de la Nueva España de Fray Toribio Motolinía es un texto que nos ha permitido observar no sólo los acontecimientos propios del escrito, sino también los diferentes procesos constructivos que se llevaron a cabo en Tlaxcala en los primeros años de la evangelización. El procedimiento utilizado en este trabajo nos permite una lectura diferente de una fuente histórica y nos puede también dar nuevas pistas cuando tratemos de estudiar el fenómeno en otras regiones de la Nueva España; es decir, tomar una crónica no sólo como fuente de acontecimientos, sino como punto de partida para la recreación de procesos constructivos arquitectónicos y urbanísticos, apoyándonos en el análisis de aquellos vestigios que aún quedan en pie.

Podemos advertir que los procesos constructivos de una ciudad, como es el caso de Tlaxcala, estuvieron en estrecha relación con las necesidades de la evangelización y que estos procesos se iban planificando según las circunstancias.

La lectura de la crónica de Fray Toribio nos ha permitido revisar la paulatina transformación del paisaje urbano de Tlaxcala, muy cercana a los ideales pretendidos de los hermanos seráficos: una ciudad ideal de prédica, enseñanza y liturgia cristiana, tal como lo habían evocado desde el Viejo Mundo. Sin embargo, no debemos olvidar la activa participación de los indígenas en todos estos procesos constructivos, en esta transfiguración de su paisaje cultural, dando comienzo al complejo programa de occidentalización urbana del paisaje americano.

Coyoacán, agosto de 1998.

\section{BIBLIOGRAFÍA CITADA}

ARTIGAS, Juan B. 1992. Capillas abiertas aisladas de México, México, UNAM.

CASAS, Bartolomé de las. 1967. Apologética Historia Sumaria, México, UNAM, Instituto de Investigaciones Históricas.

CÓRDOVA TELLO, Mario. 1992. El convento de San Miguel de Huejotzingo, Puebla. Arqueología histórica, México, I.N.A.H.

Diccionario porrúa de la lengua española. 1993. 35 a edición, Editorial Porrúa.

GIBSON, Charles. 1991. Tlaxcala en el siglo XVI, México, Gobierno del estado de Tlaxcala/F.C.E.

GRUZINSKI, Sergio. 1994. La guerra de las imágenes, México, F.C.E.

KUBLER, Georges. 1992. Arquitectura mexicana del siglo XVI, México, F.C.E. 
MENDIETA, fray Gerónimo de. 1980. Historia Eclesiástica Indiana, México, Porrua.

MOTOLINÍA, Fray Toribio. 1990. Historia de los indios de la Nueva España, (Estudio crítico, apéndices, notas e índice de Edmundo O'Gorman), México, Col. «Sepan cuántos...» n 129, Ed. Porrúa.

MUÑOZ CAMARGO, Diego. 1981. Descripción de la Ciudad y Provincia de Tlaxcala..., Ed. facs. del Manuscrito de Glasgow con un estudio preliminar de René Acuña, México, Instituto de Investigaciones Filológicas, UNAM.

SEMPAT ASSADOURIAN, Carlos y Andrea MARTÍNEZ BARACS (comps.). 1991. Tlaxcala, textos de su historia, siglo XVI, Vol. 6, Tlaxcala, Gobierno del Estado de Tlaxcala, CONACULTA.

TOUSSAINT, Manuel. 1927. «Un templo cristiano sobre el Palacio de Xicoténcatl» en Revista Mexicana de Estudios Históricos, Tomo I, $\mathrm{N}^{\circ} 4$ (julio y agosto), Editorial Cultura, México, pp. 173-180.

WECKMANN, Luis. 1984. La Herencia Medieval de México, (2 tomos), México, El Colegio de México. 